\title{
Headache due to Spontaneous Spinal Cerebrospinal Fluid Leaks
}

\author{
Michimasa Fujiwara $^{1}$, Eiji Moriyama ${ }^{2}$ and Tooru Araki ${ }^{1}$
}

Key words: headache, intracranial hypotension, spinal cerebrospinal fluid leaks

(Intern Med 58: 461, 2019)

(DOI: 10.2169/internalmedicine.1136-18)
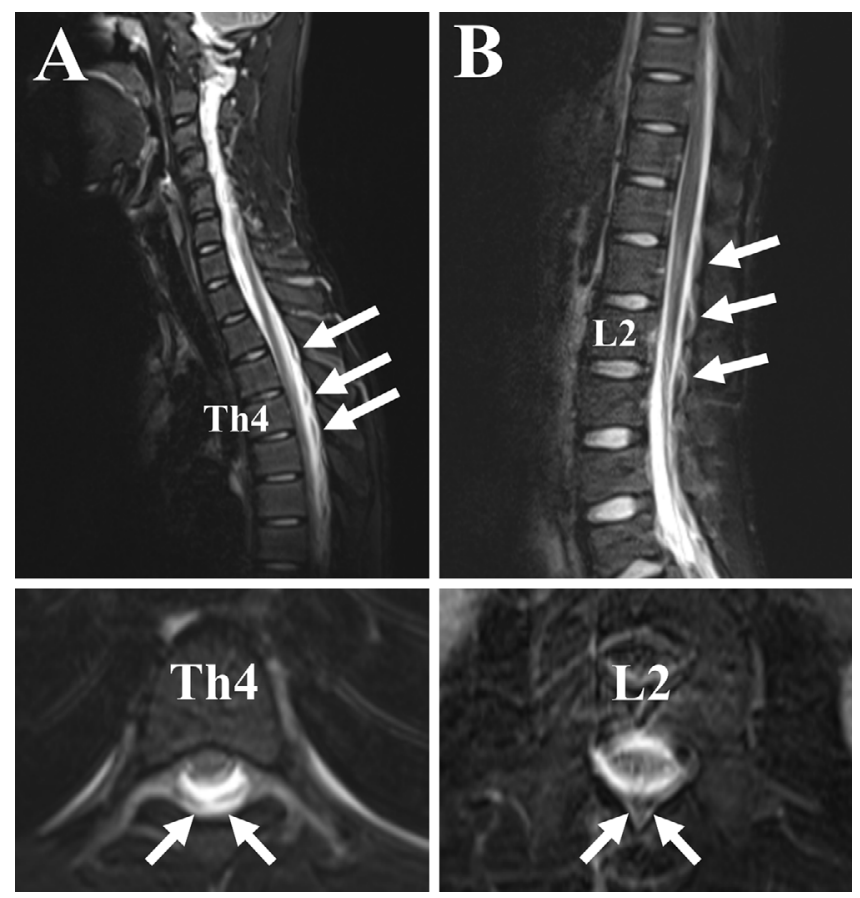

Picture.

A 15-year-old boy presented to the emergency department with severe headache one day after a football game. He received no severe contact injuries during the game. Despite receiving intravenous hydration shortly after the game, his symptoms subsequently worsened. A physical examination revealed upper limb numbness and headache that increased in severity upon sitting or resuming standing. Brain magnetic resonance imaging (MRI) was normal, but T2-weighed MRI of the spine revealed cerebrospinal fluid leakage at the thoracic (Picture A, arrow) and lumbar (Picture B, arrow) spine. Spontaneous intracranial hypotension due to spontaneous spinal cerebrospinal fluid leaks was diagnosed. An epidural blood patch resulted in the resolution of the symptoms and the disappearance of the abnormal leaks on follow-up MRI. This treatable disorder has emerged as a significant cause of orthostatic headaches (1) that can compromise the quality of life if left untreated (2). Spinal MRI is a useful screening tool for detecting leaks.

The authors state that they have no Conflict of Interest (COI).

\section{References}

1. Mokri B. spontaneous low pressure, low CSF volume headaches: spontaneous CSF leaks. Headache 53: 1034-1053, 2013.

2. Mokri B, Schievink WI. Headache associated with abnormalities in intracranial structure or function: low-cerebrospinal-fluidpressure headache. In: Wolff's Headache and Other Head Pain. 8th ed. Silberstein SD, Lipton RB, Dodick DW, Eds. Oxford, New York, 2007: 513-531.

The Internal Medicine is an Open Access journal distributed under the Creative Commons Attribution-NonCommercial-NoDerivatives 4.0 International License. To view the details of this license, please visit (https://creativecommons.org/licenses/ by-nc-nd/4.0/).

\footnotetext{
${ }^{1}$ Department of Pediatrics, National Hospital Organization Fukuyama Medical Center, Japan and ${ }^{2}$ Department of Neurosurgery, National Hospital Organization Fukuyama Medical Center, Japan

Received: March 6, 2018; Accepted: July 17, 2018; Advance Publication by J-STAGE: September 12, 2018

Correspondence to Dr. Michimasa Fujiwara, fujiwara_michimasa@fukuyama-hosp.go.jp
}

(C) 2019 The Japanese Society of Internal Medicine. Intern Med 58: 461, 2019 